\title{
miR-1303 promotes the proliferation, migration and invasion of prostate cancer cells through regulating the Wnt/ $\beta$-catenin pathway by targeting DKK3
}

\author{
BO LIU ${ }^{1 *}$, WEIDONG ZHOU $^{1 *}$, HUIYANG JIANG ${ }^{1}$, ZHENDONG XIANG $^{1}$ and LEI WANG ${ }^{1,2}$ \\ ${ }^{1}$ Department of Urology, Tongji Hospital, Tongji University of Medicine, Shanghai 200065; \\ ${ }^{2}$ Department of Urology, Ningbo No. 7 Hospital, Ningbo, Zhejiang 315202, P.R. China
}

Received December 13, 2018; Accepted August 22, 2019

DOI: $10.3892 /$ etm.2019.8120

\begin{abstract}
MicroRNA-1303 (miR-1303) is involved in the tumorigenesis and progression of several cancers, and yet the role of miR-1303 in prostate cancer ( $\mathrm{PCa}$ ) and its underlying mechanism are unknown. To explore this issue, the present study aimed to use PCa tissues, cell lines and a PCa-engrafted mouse model to determine the expression and roles of miR-1303 in PCa. Furthermore, a series of experiments were conducted to explore the underlying mechanisms of action of miR-1303 in PCa cells. miR-1303 was demonstrated to be highly expressed in PCa tissues and cell lines. The level of miR-1303 expression was closely associated with higher Gleason scores and a more developed tumor stage in patients with PCa, and patients with higher levels of miR-1303 displayed a reduced overall survival rate. miR-1303 overexpression promoted the proliferation, migration and invasion of $\mathrm{PCa}$ cells. In vivo experiments showed that miR-1303 inhibition suppressed the growth of PCa tumors in mice. Additionally, dickkopf Wnt signaling pathway inhibitor 3 (DKK3) was identified as a target of miR-1303. Knockdown of miR-1303 suppressed the proliferation, migration and invasion of $\mathrm{PCa}$ cells, increased DKK3 expression, and inhibited the activity of the Wnt/ $\beta$-catenin pathway. In conclusion, miR-1303 may promote proliferation, migration and invasion of $\mathrm{PCa}$ cells through activating the $\mathrm{Wnt} / \beta$-catenin pathway by regulating DKK3 expression. These results indicated that miR-1303 may be considered as a potential biomarker for PCa treatment.
\end{abstract}

Correspondence to: Dr Lei Wang, Department of Urology, Ningbo No. 7 Hospital, 718 South Second West Road, Luotuo Street, Ningbo, Zhejiang 315202, P.R. China

E-mail: wangleiwlei@163.com

*Contributed equally

Key words: microRNA-1303, dickkopf Wnt signaling pathway inhibitor 3, Wnt/ $\beta$-catenin pathway, prostate cancer

\section{Introduction}

Prostate cancer ( $\mathrm{PCa})$ is the second most frequently diagnosed cancer and the fifth cause of cancer-related death in men worldwide (1,2). Patients with PCa in the early stages can be treated with prostatectomy, chemotherapy, or radiotherapy, and the prognosis from these therapies is favorable $(3,4)$; however, most of the therapy methods have side effects and there is a limited ability to treat patients in the late stages (5). Although androgen deprivation therapy is the standard treatment for patients with $\mathrm{PCa}$ in the advanced stages, owing to the high sensitivity of PCa cells to hormone deprivation, the tumor will develop to an end-stage metastatic disease, referred to as castration-resistant $\mathrm{PCa}$, to overcome the hormone inhibition following sustained treatment $(4,6)$. Therefore, patients with recurrent or metastatic PCa have lower 5-year survival rates $(\sim 30 \%)$ compared with patients with local or regional $\mathrm{PCa}$ ( $100 \%$ ) (7-9). Therefore, exploring the molecular mechanism underlying PCa development may aid in improving diagnosis and prognosis, and further improving the survival rate of patients with $\mathrm{PCa}$.

MicroRNAs (miRNAs) are a class of single-stranded, small, non-coding RNAs that can regulate $\sim 60 \%$ of the protein-coding gene at the post-transcriptional level $(10,11)$. miRNAs can target oncogenes or tumor suppressor genes to regulate different biological processes, such as cell apoptosis, metastasis and proliferation (12). Thus, evaluation of miRNA function in cancers is a hotspot in molecular oncology (10). For example, miR-148a in colitis-associated tumorigenesis can act as a tumor suppressant via inhibiting NF- $\kappa$ B/STAT3 signaling (13). miR-130a can function as an oncogenic miRNA to promote cell survival and tumor growth through targeting PTEN (14). Previous, studies have also suggested that miR-1303 is related to the tumorigenesis and development of several cancers including neuroblastoma, gastric cancer and colorectal cancer (15-17); however, there are no reports of the roles of miR-1303 in PCa.

The Wnt/ $\beta$-catenin pathway is a highly conserved, intercellular signaling cascade and a key regulator of various cellular processes (18). Aberrant activation of the Wnt/ $\beta$-catenin pathway is closely associated with the development of different cancers including PCa (19). A previous study has indicated that 
the Wnt/ $\beta$-catenin pathway has an important role in PCa cell proliferation, invasion and differentiation (20). Li et al have demonstrated that PHD finger protein 21B (PHF21B) overexpression activates the $\mathrm{Wnt} / \beta$-catenin pathway to promote PCa stem cell-like phenotype (21). Flores et al have suggested that targeting the $\mathrm{Wnt} / \beta$-catenin pathway may enhance the efficacy of taxane chemotherapy in patients with PCa in the advanced stages of disease progression (22). Hence, it is clinically important to understand the roles of the $\mathrm{Wnt} / \beta$-catenin pathway in PCa.

In this present study, miR-1303 expression was determined in PCa tissues and cell lines, and the effects of miR-1303 on the proliferation, migration and invasion of $\mathrm{PCa}$ cells were assessed. Subsequently, dickkopf Wnt signaling pathway inhibitor 3 (DKK3) was identified as a direct target of miR-1303. Finally, the Wnt/ $\beta$-catenin pathway was found to be involved in the potentiating effects of miR-1303 in the proliferation, migration and invasion of PCa cells.

\section{Materials and methods}

Bioinformatics analysis. MicroRNA-mRNA binding sites were predicted using computer-aided algorithms obtained from TargetScan (version 7.2; http://www.targetscan. org/vert_72/) (23). Given the critical roles of the Wnt/ $\beta$-catenin pathway in the development of PCa $(19,20)$, DKK3, as a key inhibitor of the Wnt/ $\beta$-catenin pathway (24), was subsequently chosen as the target for miR-1303.

Clinical sample collection. Primary PCa tissues and adjacent normal prostate tissues were obtained from 30 patients with $\mathrm{PCa}$. These patients underwent surgery in Tongji Hospital (Shanghai, China) between January 2012 and October 2013. Before surgery, no patients were treated with radiotherapy or chemotherapy. Tissues were immediately frozen at $-80^{\circ} \mathrm{C}$. The patients were followed up for 50 months after surgery. The Human Research Ethics Committee of Tongji Hospital approved this experiment, and informed consent was obtained from each patient.

Cell lines and cell culture. PCa cell lines (DU145, PC-3, 22Rv1 and LNCAP) and a human normal prostate epithelial cell line (RWPE-1) were purchased from the Cellular Resource Center of Shanghai Institutes for Biological Sciences, Chinese Academy of Sciences. Cells were incubated in DMEM (Gibco; Thermo Fisher Scientific, Inc.) supplemented with 10\% FBS (Gibco; Thermo Fisher Scientific, Inc.), $100 \mu \mathrm{g} / \mathrm{ml}$ streptomycin and $100 \mathrm{U} / \mathrm{ml}$ penicillin in a humidified incubator containing $5 \% \mathrm{CO}_{2}$ at $37^{\circ} \mathrm{C}$.

Cell transfection. DU145 cells were seeded $\left(4 \times 10^{5}\right.$ cells $\left./ \mathrm{ml}\right)$ in a 6-well plate and incubated in DMEM medium with $10 \%$ FBS at $37^{\circ} \mathrm{C}$ for $24 \mathrm{~h}$ prior to transfection. miR-1303 inhibitor, miR-1303 mimics, siRNA targeting DKK3 (siDKK3) and their corresponding negative controls (NC) were obtained from Shanghai GenePharma Co., Ltd. A total of $100 \mathrm{nM}$ siDKK3 (5'-CUCCACCCUCGUCAGACAUAUAUAA-3'), $30 \mathrm{nM}$ miRNA-1303 mimics (5'-UUUAGAGACGGGGUCUUG CUCU-3'), $30 \mathrm{nM}$ mimic control (5'-CCUGACCUCAGGGUU GAAUGUU-3'), 100 nM miRNA-1303 inhibitor (5'-AGAGCA
AGACCCCGUCUCUAAA-3') or $100 \mathrm{nM}$ inhibitor control (5'-AUUCACCUAAGGAUGACGUCCA-3') were transfected into DU145 cells in 6-well plates using $2.5 \mu$ l Lipofectamine ${ }^{\circledR}$ 3000 (Invitrogen; Thermo Fisher Scientific, Inc.) according to the manufacturer's protocol. After $6 \mathrm{~h}$ transfection, the transfected cells were incubated in DMEM medium with $10 \%$ FBS at $37^{\circ} \mathrm{C}$ with $5 \% \mathrm{CO}_{2}$ for another $48 \mathrm{~h}$ before harvest for subsequent experiments.

Reverse transcription-quantitative PCR (RT-qPCR). TRIzol ${ }^{\circledR}$ reagent (Invitrogen; Thermo Fisher Scientific, Inc.) was used to extract total RNA from PCa tissues $(50 \mathrm{mg})$ and cells $\left(5 \times 10^{6}\right.$ cells $\left./ \mathrm{ml}\right)$ according to the manufacturer's protocol. SMARTScribe ${ }^{\mathrm{TM}}$ Reverse Transcriptase, dNTP Mix and random primers (hexadeoxyribonucleotide mix: $\mathrm{pd}(\mathrm{N}) 6)$, all which purchased from Takara Biotechnology Co., Ltd., were used to generate cDNA from RNA.

For mature miR-1303 detection, miRNA was extracted by miRNeasy Mini kit (Qiagen $\mathrm{GmbH}$ ). The TaqMan microRNA Reverse Transcription Kit (Applied Biosystems; Thermo Fisher Scientific, Inc.) were used to reverse transcribe RNA into cDNA according to the manufacturer's protocol, using the specific miRNA primers (5'-GTCGTATCCAGTGCAGGG TCCGAGGTATTCGCACTGGATACGACAGAGCAAG-3'; GenScript Biotechnology).

Quantitative PCR was performed using a SYBR ${ }^{\circledR}$ Premix Ex Taq ${ }^{\mathrm{TM}}$ RT-PCR Kit (Takara Biotechnology Co., Ltd.) and an ABI 7500 Fast Real-Time PCR system. Relative expression mRNAs and miRNAs were evaluated using the $2^{-\Delta \Delta C q}$ method (25) and normalized to $\beta$-actin and U6, respectively. The thermocycling conditions for the qPCR were listed as follows: Initial denaturation at $50^{\circ} \mathrm{C}$ for $2 \mathrm{~min}, 95^{\circ} \mathrm{C}$ for $10 \mathrm{~min}$; followed by 40 cycles of $95^{\circ} \mathrm{C}$ for $15 \mathrm{sec}$ and $60^{\circ} \mathrm{C}$ for $60 \mathrm{sec}$. Primers sequences were as follows: miR-1303 forward, 5'-ACGGGGTCTTGCTCTAAAAA-3' and reverse, 5'-CAGTGCGTGTCGTGGAGT-3'; DKK3 forward, 5'-CTG GGAGCTAGAGCCTGATG-3'; and reverse, 5'-TCATAC TCATCGGGGACCTC-3'; $\beta$-actin forward, 5'-AGCCTCGCC TTTGCCGA-3' and reverse, 5'-CTGGTGCCTGGGGCG-3'; U6 forward, 5'-CTCGCTTCGGCAGCACA-3' and reverse, 5'-AACGCTTCACGAATTTGCGT-3'.

Cell Counting kit 8 (CCK-8) assay. After 48 h transfection, cells were collected, seeded ( $1 \times 10^{4}$ cells/well) in 96 -well plates and incubated in DMEM containing $10 \% \mathrm{FBS}$ at $37^{\circ} \mathrm{C}$ for 24 , 48 and $72 \mathrm{~h}$. According to the manufacturer's protocol of the CCK-8 detection kit (Engreen Biosystem Co, Ltd.), CCK-8 solution $(10 \mu \mathrm{l})$ was added to the cells at the different time points and incubated for a further $4 \mathrm{~h}$ at $37^{\circ} \mathrm{C}$. A microplate reader was used to measure the proliferation of the cells at an absorbance of $450 \mathrm{~nm}$.

Colony formation assay. After transfection, cells were trypsinized, collected and added into 6-well plates (200 cells/ well). The cells were cultured in DMEM containing $10 \%$ FBS at $37^{\circ} \mathrm{C}$ under $5 \% \mathrm{CO}_{2}$ for 2 weeks, replacing the culture medium every 3 days. The cells were fixed with methanol at room temperature for $15 \mathrm{~min}$, stained with $1 \%$ crystal violet for $30 \mathrm{~min}$ at room temperature and images (containing $>50$ cells/colony) were captured using a light microscope 
(magnification, x100; Olympus Corporation). The colony number was counted manually.

Wound healing assay. The transfected cells were incubated to $100 \%$ confluence in 6 -well plates. Subsequently, a straight line was scratched using a sterile $100 \mu \mathrm{l}$ pipette tip through the cell monolayer. After removing the debris, the cells were cultured in serum-free DMEM at $37^{\circ} \mathrm{C}$ under $5 \% \mathrm{CO}_{2}$ for $24 \mathrm{~h}$ and then images were captured with an Olympus BX51 light microscope (magnification, x100; Olympus Corporation). The degree of wound closure was calculated using Image Pro-Plus version 6.0 (Media Cybernetics, Inc.) with the following formula: Average width of scratches $=$ area of scratches/height of scratches; the degree of wound closure $=($ Average width of scratches at $24 \mathrm{~h} /$ Average width of scratches at $0 \mathrm{~h}$ ) $\times 100 \%$.

Invasion assay. Cellular invasion was determined in 24-well plates using a Transwell chamber ( $8 \mu \mathrm{m}$ pore; BD Biosciences) pre-coated with Matrigel. Briefly, cells were transfected for $24 \mathrm{~h}$ as aforementioned, suspended in serum-free DMEM and added into the upper Transwell chamber. The medium including a chemoattractant (10\% FBS) was placed into the lower chamber. After incubation for $24 \mathrm{~h}$ at $37^{\circ} \mathrm{C}$, the cells that invaded the chamber lower side were fixed with $4 \%$ paraformaldehyde at room temperature for $30 \mathrm{~min}$, stained with $0.1 \%$ crystal violet at room temperature for $20 \mathrm{~min}$, and washed with PBS. Stained cells were counted and images were captured with an Olympus BX51 light microscope (Olympus Corporation) at x200 magnification.

Luciferase reporter assay. The miR-1303 wild-type (WT) and mutant (MUT) target sequences in the 3'-untranslated region (UTR) of the DKK3 gene were obtained from Sangon Biotech Co., Ltd. WT and MUT DKK3 luciferase reporter plasmids were generated through cloning the above two DNA fragments into the psiCHECK-2 vector (Promega Corporation). The cells were cultured at a density of $1.0 \times 10^{5}$ cells/well in 24 -well plates and co-transfected with DKK3-MUT or DKK3-WT plasmids; and miR-1303 mimics or NC mimics using Lipofectamine 3000 (Invitrogen) at $37^{\circ} \mathrm{C}$ for $48 \mathrm{~h}$, the Dual Luciferase Reporter Assay kit (Promega Corporation) was utilized to detect the luciferase activities, which were normalized to the corresponding Renilla luciferase activity.

Western blotting. RIPA lysis buffer (Beyotime Institute of Biotechnology) was used to extract cell lysates. Protein concentration was quantified using Bicinchoninic Acid Assay, and then $20 \mu \mathrm{g}$ proteins were separated equally using 10\% SDS-PAGE and electro-transferred onto PVDF membranes. The membranes were blocked using 5\% non-fat milk at room temperature for $1 \mathrm{~h}$ and cultured overnight with primary antibodies against DKK3 (cat. no. 10365-1-AP; dilution 1:1,000; ProteinTech Group, Inc.), $\beta$-catenin (cat. no. 8480; dilution 1:1,000; Cell Signaling Technology, Inc.), c-Myc (cat. no. 13987; dilution 1:1,000; Cell Signaling Technology, Inc.), GAPDH (cat. no. 8884; dilution 1:1,000; Cell Signaling Technology, Inc.) or cyclin D1 (cat. no. 55506; dilution 1:1,000; Cell Signaling Technology, Inc.) at $4{ }^{\circ} \mathrm{C}$. After washing with TBS buffer containing $0.05 \%$ Tween-20 (TBS-T), the membranes were incubated with a horseradish peroxidase-conjugated goat anti-rabbit secondary antibody (cat. no. SA00001-2, dilution 1:2,000; ProteinTech Group, Inc.) at $25^{\circ} \mathrm{C}$ for $1 \mathrm{~h}$. Subsequently, the membranes were rinsed with blocking solution at room temperature for $15 \mathrm{~min}$. Protein bands visualized using an ECL system (Immun-Star ${ }^{\text {TM }}$ HRP chemiluminescent detection kit, Bio-Rad Laboratories, Inc.). Densitometric analysis was determined by Quantity One software (version 4.62; Bio-Rad Laboratories Inc.) and normalized to the internal control, GAPDH.

Immunofluorescence microscopy. After $48 \mathrm{~h}$ of transfection, cells cultured $\left(1 \times 10^{6}\right.$ cells $\left./ \mathrm{ml}\right)$ on coverslips in a six-well plate for $24 \mathrm{~h}$ were fixed with $4 \%$ paraformaldehyde at $25^{\circ} \mathrm{C}$ for $15 \mathrm{~min}$, permeabilized with $0.05 \%$ Triton $\mathrm{X}-100$ for $10 \mathrm{~min}$, and blocked with $5 \%$ goat serum (Invitrogen; Thermo Fisher Scientific, Inc.) in PBS for $1 \mathrm{~h}$ at room temperature. Cells were then incubated with primary antibodies against $\beta$-catenin (1:100; Cell Signaling Technology, Inc.) overnight at $4^{\circ} \mathrm{C}$. Subsequently, the cells were cultured with Alexa Fluor ${ }^{\circledR} 488$-conjugated donkey anti-rabbit IgG antibody (cat. no. 4412, dilution 1:500 dilution; Cell Signaling Technology, Inc.) in darkness for $1 \mathrm{~h}$ at room temperature. DAPI (1:4,000; Beyotime Institute of Biotechnology) was applied to counterstain the nuclei for $5 \mathrm{~min}$ at room temperature. The samples were mounted on slides using an antifade reagent (Beijing Solarbio Science \& Technology Co., Ltd.) and examined under a laser-scanning confocal microscope (Leica Microsystems $\mathrm{GmbH}$ ) at x200 magnification. The \% positive $\beta$-catenin cells were analyzed using the Image Pro-Plus software (version 6.0, Media Cybernetics, Inc.,) and calculated using the following formula: $\%$ positive $\beta$-catenin cells $=($ cells with nucleus positive for $\beta$-catenin/total cells) x100\%.

Immunohistochemistry (IHC). Tumor tissues were fixed with $4 \%$ paraformaldehyde for $24 \mathrm{~h}$ at $25^{\circ} \mathrm{C}$, dehydrated with an ethanol series and paraffin embedded. The tissues were cut into $4 \mu \mathrm{m}$ section. These sections were deparaffinized with xylene and rehydrated using a graded ethanol series. Antigen retrieval was performed at $100^{\circ} \mathrm{C}$ in citrate buffer $(\mathrm{pH} \mathrm{6.0)}$. Each section was immersed in $3 \% \mathrm{H}_{2} \mathrm{O}_{2}$ at $25^{\circ} \mathrm{C}$ for $20 \mathrm{~min}$ to block endogenous peroxidase activity, sealed with $5 \%$ normal goat serum (Beijing Solarbio Biotechnology Co., Ltd.) at $23^{\circ} \mathrm{C}$ for $1 \mathrm{~h}$ and then incubated with primary antibodies (ProteinTech Group, Inc.) against Ki67 (cat. no. 27309-1-AP, dilution 1:4,000) and DKK3 (cat. no. 10365-1-AP, dilution $1: 500)$ at $4^{\circ} \mathrm{C}$ overnight. Next, the sections were cultured with horseradish peroxidase-conjugated secondary antibodies (cat. no. ab150077; dilution 1:200; Abcam) for $30 \mathrm{~min}$ at $25^{\circ} \mathrm{C}$, diaminobenzidine working solution was added for $6 \mathrm{~min}$, and counterstained with hematoxylin. Finally, the samples were visualized and analyzed using a light microscope (Olympus Corporation; magnification, x200).

Tumor formation in nude mice. A total of 20 male BALB/C nude mice (age, 6 weeks; weight, 18-22 g) were purchased from The Experimental Animal Center of Tongji Hospital. The mice were randomly divided into two groups (10/group), housed in a specific pathogen-free environment (temperature, $21-23^{\circ} \mathrm{C}$; humidity, $50-60 \%$ ) under a 12 -h light/dark cycle and were allowed free access to water and food. DU145 cells 
A

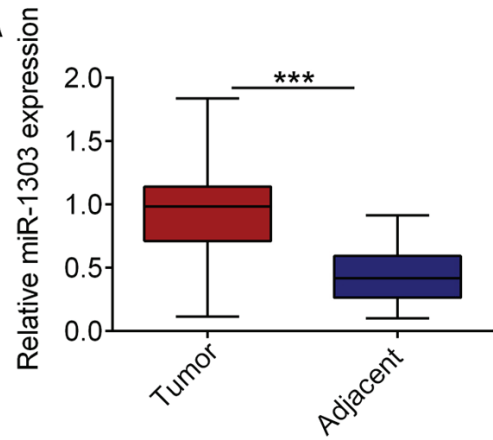

B

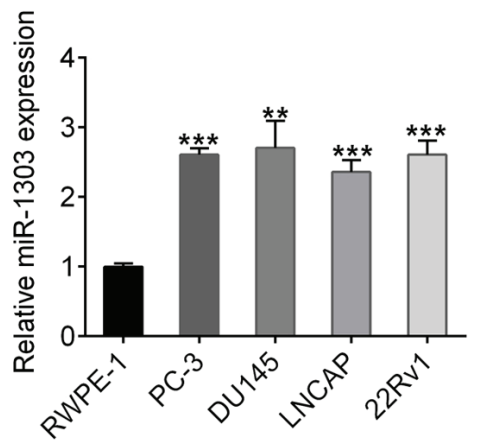

C

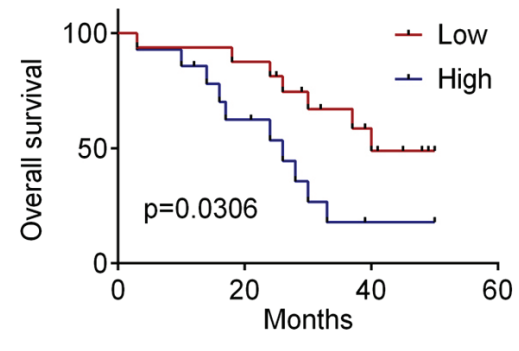

Figure 1. High expression of miR-1303 in PCa tissues and cell lines. (A) miR-1303 expression in PCa tissues and adjacent normal tissues was determined by RT-qPCR. (B) RT-qPCR was also used to detect the expression levels of miR-1303 in PCa cell lines PC-3, DU145, LNCAP and 22Rv1 and the human normal prostate epithelial cell line RWPE-1. (C) The overall survival was analyzed for two groups of patients with PCa with low or high expression levels of miR-1303. ${ }^{* * *} \mathrm{P}<0.001$ and $^{* *} \mathrm{P}<0.01$ vs. Adjacent or RWPE-1. miR-1303, microRNA-1303; PCa, prostate cancer; RT-qPCR, reverse transcription-quantitative PCR.

were harvested at the logarithmic growth period at a density of $1 \times 10^{7}$ cells $/ \mathrm{ml}$, and were subcutaneously injected into the right side of the back ribs of the mice. When the tumor diameter reached 6-8 mm, miR-1303 inhibitor/In vivo-jetPEI ${ }^{\circledR}$ (Polyplus-transfection SA) or NC inhibitor/In vivo-jetPEI ${ }^{\circledR}$ complexes were injected into the xenograft tumor every 4 days for 30 days (a total of 8 times), where In vivo-jetPEI ${ }^{\circledR}$ was the delivery agent (concentration miRNA used, $10 \mu \mathrm{g}$; In vivo-jetPEI reagent used, $1.2 \mu \mathrm{l}$ in $100 \mu \mathrm{l}$ of $5 \%$ glucose per injection). The sizes of the tumors were determined using a Vernier caliper every 6 days for 30 days. The volume was calculated using the following formula: $\mathrm{V}=0.5 \mathrm{~L} \mathrm{X} \mathrm{W}^{2}$, where $\mathrm{L}$ represents the long diameter and $\mathrm{W}$ represents the short diameter. All mice were sacrificed on day 30 (the tumor volume $<1,500 \mathrm{~mm}^{3}$; the tumor diameter $<1.5 \mathrm{~cm}$ ). All procedures were approved by the Animal Experimental Committee of Tongji Hospital.

Statistical analysis. The data are presented as the mean \pm standard deviation and were analyzed by SPSS software (version 13.0; SPSS Inc.). All experiments were repeated at least three independent times. Student's t-test was used to evaluate the differences between two groups. One-way ANOVA followed by Tukey's test was performed for multiple comparisons. The $\chi^{2}$ test was applied to determine the association between miR-1303 expression and clinical feature in patients with $\mathrm{PCa}$. The relationship between miR-1303 level and patient overall survival time was assessed by the Kaplan-Meier method and log-rank test. $\mathrm{P}<0.05$ was considered to indicate a statistically significant difference.

\section{Results}

miR-1303 is highly expressed in PCa tissues and cell lines and predicts poor overall survival. To explore the role of miR-1303 in PCa, miR-1303 expression levels were determined in PCa tissues and cell lines using RT-qPCR (Fig. 1). miR-1303 was highly expressed in PCa tissues compared to the corresponding adjacent normal tissues ( $\mathrm{P}<0.001$; Fig. 1A). Similarly, compared with human normal prostate epithelial cell line RWPE-1, miR-1303 expression levels were significantly higher in PCa cell lines PC-3, 22Rv1, LNCAP and
DU145 (P<0.05; Fig. 1B). As DU145 cells showed the greatest mean miR-1303 expression relative to RWPE-1 cells, they were chosen for all subsequent experiments. These results suggested that miR-1303 was highly expressed in PCa tissues and cell lines.

$\chi^{2}$ analyses were used to determine the association between miR-1303 expression and clinical features in $\mathrm{PCa}$ patients (Table I). The median expression level of miR-1303 designated as a cut-off value was utilized to divide the patients into miR-1303 high expression $(n=14)$ and miR-1303 low expression $(n=16)$ groups. Statistical analysis indicated that higher miR-1303 expression levels were associated with higher Gleason scores $(\mathrm{P}=0.017)$ and more developed tumor stages $(\mathrm{P}=0.024)$; no significant associations were made between miR-1303 expression levels and age, prostate diameter, lymph-node metastasis or the presentation of multiple lesions ( $\mathrm{P}>0.05$; Table I). The relationship between the miR-1303 level and patient overall survival time was assessed by the Kaplan-Meier method and log-rank test (Fig. 1C). Patients with high levels of miR-1303 had a worse overall survival rate in comparison with patients with low levels of miR-1303.

miR-1303 promotes the proliferation, migration and invasion of PCa cells. To investigate the role of miR-1303 in PCa cells, DU145 cells were transfected with miR-1303 mimics, miR-1303 inhibitor or the corresponding negative controls, and CCK-8, colony formation, wound healing and Matrigel assays were used to analyze the effects on the cells (Fig. 2). RT-qPCR analysis indicated that miR-1303 mimics significantly increased miR-1303 expression in PCa cells (Fig. 2A), whereas miR-1303 inhibitor decreased the expression levels of miR-1303 (both $\mathrm{P}<0.001$ ), which indicated the effective transfection of miR-1303 mimics or inhibitor. The proliferation of $\mathrm{PCa}$ cells transfected with miR-1303 mimics or inhibitor was detected by CCK- 8 and colony formation assays. In the CCK-8 assay, the proliferation was enhanced in DU145 cells transfected with miR-1303 mimics, whereas the transfection of miR-1303 inhibitor reduced the cell proliferation (both $\mathrm{P}<0.001$; Fig. $2 \mathrm{~B}$ ). Furthermore, colony formation assay results demonstrated that the colony number of DU145 cells was increased by miR-1303 mimics transfection, whereas the number was decreased by miR-1303 
Table I. Association of miR-1303 and patient clinicopathological features.

miR-1303 expression

\begin{tabular}{|c|c|c|c|c|}
\hline \multirow[b]{2}{*}{ Clinicopathological characteristic } & \multirow[b]{2}{*}{ Number $(n=30)$} & & \multirow[b]{2}{*}{$\chi^{2} \mathrm{P}$-value } \\
\hline & & Low $(n=16)$ & High $(n=14)$ & \\
\hline Age (years) & & & & 0.389 \\
\hline$\geq 65$ & 19 & 9 & 10 & \\
\hline$<65$ & 11 & 7 & 4 & \\
\hline Prostate diameter $(\mathrm{cm})$ & & & & 0.282 \\
\hline$\geq 2.5$ & 14 & 6 & 8 & \\
\hline$<2.5$ & 16 & 10 & 6 & \\
\hline Gleason score & & & & 0.017 \\
\hline$\geq 7$ & 19 & 7 & 12 & \\
\hline$<7$ & 11 & 9 & 2 & \\
\hline Lymph-node metastasis & & & & 0.51 \\
\hline Yes & 11 & 5 & 6 & \\
\hline No & 19 & 11 & 8 & \\
\hline Tumor stage & & & & 0.024 \\
\hline $\mathrm{T} 2$ & 13 & 10 & 3 & \\
\hline $\mathrm{T} 3-\mathrm{T} 4$ & 17 & 6 & 11 & \\
\hline Multiple lesions & & & & 0.919 \\
\hline Positive & 19 & 10 & 9 & \\
\hline Negative & 11 & 6 & 5 & \\
\hline
\end{tabular}

miR-1303, microRNA-1303.

inhibitor transfection (both $\mathrm{P}<0.001$; Fig. 2C). The migratory ability of PCa cells was determined by wound healing assay (Fig. 2D). miR-1303 mimics accelerated wound closure in cell monolayers, whereas miR-1303 inhibitor suppressed wound closure compared with the respective control groups (both $\mathrm{P}<0.05$ ). The invasive ability of PCa cells was measured by Matrigel assay (Fig. 2E). The invasive cell numbers were increased by miR-1303 mimics, but the number was reduced by miR-1303 inhibitor transfection compared with respective control groups $(\mathrm{P}<0.001)$. These results suggested that miR-1303 may promote the proliferation, migration and invasion of PCa cells.

$D K K 3$ is a direct target of miR-1303. To investigate the molecular mechanism of miR-1303 in PCa tumorigenesis, TargetScan was utilized to identify putative target genes of miR-1303. The results revealed that the 3'-UTR of DKK3 contained a predicted target site for miR-1303. To verify this relationship, luciferase reporter, RT-qPCR and western blotting assays were performed (Fig. 3). DKK3-WT or DKK3-MUT was co-transfected with miR-1303 mimics or NC mimics into DU145 cells; miR-1303 mimics greatly decreased the luciferase activity of DKK3-WT, but the luciferase activity in DKK3-MUT had no obvious alterations (Fig. 3A). Thus, these results demonstrated that DKK3 was a direct target of miR-1303. Furthermore, RT-qPCR and western blotting showed that the mRNA and protein expression of DKK3 were greatly decreased by miR-1303 mimics and increased by miR-1303 inhibitors (all $\mathrm{P}<0.001$; Fig. $3 \mathrm{~B}$ and $\mathrm{C}$, respectively).
These data demonstrated that miR-1303 negatively regulates DKK3 expression.

Knockdown of miR-1303 suppresses the proliferation, migration and invasion of $P C$ a cells by regulating DKK3. Further analysis was performed to determine whether the effects of miR-1303 on PCa cells were related to DDK3 expression (Fig. 4). The expression levels of DKK3 mRNA in DU145 cells were successfully knocked down by siDKK3 transfection compared with the control siRNA group $(\mathrm{P}<0.001$; Fig. 4A). Thus, the transfection of siDKK3 was effective. In addition, western blotting demonstrated that miR-1303 inhibitor considerably increased the level of DKK3 as compared to NC inhibitor group, but siDKK3 co-transfection effectively inhibited the miR-1303 induced upregulation of DKK3 ( $\mathrm{P}<0.001$; Fig. 4B). CCK-8 assay results indicated that the proliferation of DU145 cells was decreased by miR-1303 inhibitor and this effect was abolished after co-transfection with siDKK3 ( $\mathrm{P}<0.001$; Fig. 4C). In addition, the colony formation assay demonstrated that the decrease of colony numbers of DU145 cells caused by miR-1303 inhibitor was reversed after siDKK3 co-transfection $(\mathrm{P}<0.001$; Fig. 4D). The Matrigel assay and wound healing assay showed that miR-1303 inhibitor suppressed the invasion and migration of DU145 cells, respectively, whereas siDKK3 and miR-1303 inhibitor co-transfection significantly improved the invasive and migratory abilities compared to miR-1303 alone transfections $(\mathrm{P}<0.01$; Fig. 4E and F). Collectively, these data suggested that the knockdown of miR-1303 inhibited the proliferation, migration and invasion of PCa cells by regulating DKK3 expression. 
A

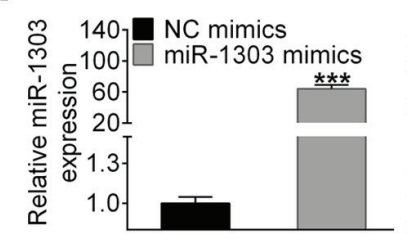

C

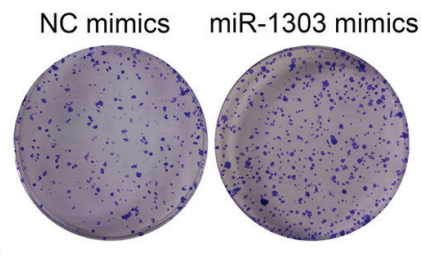

D

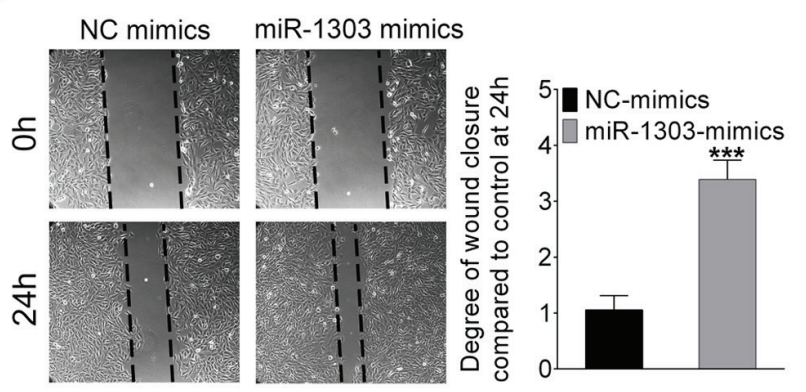

$\mathbf{E}$

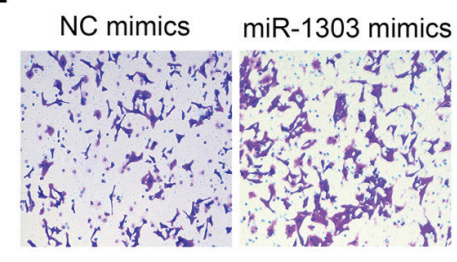

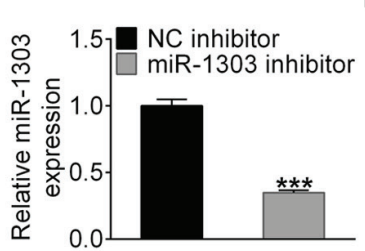
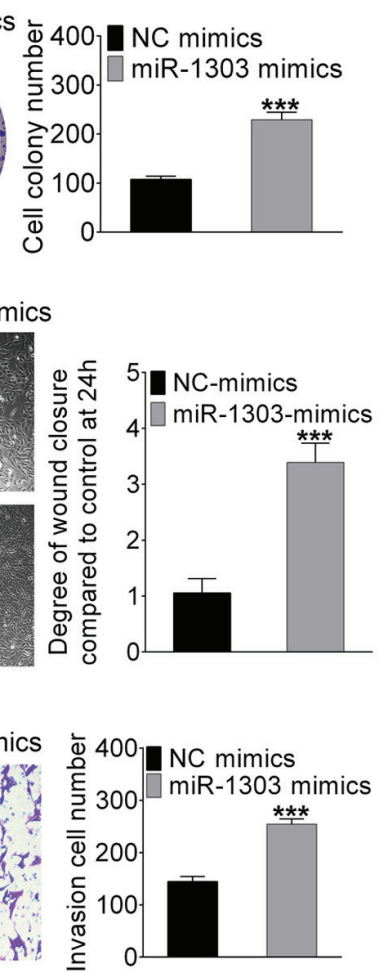

B
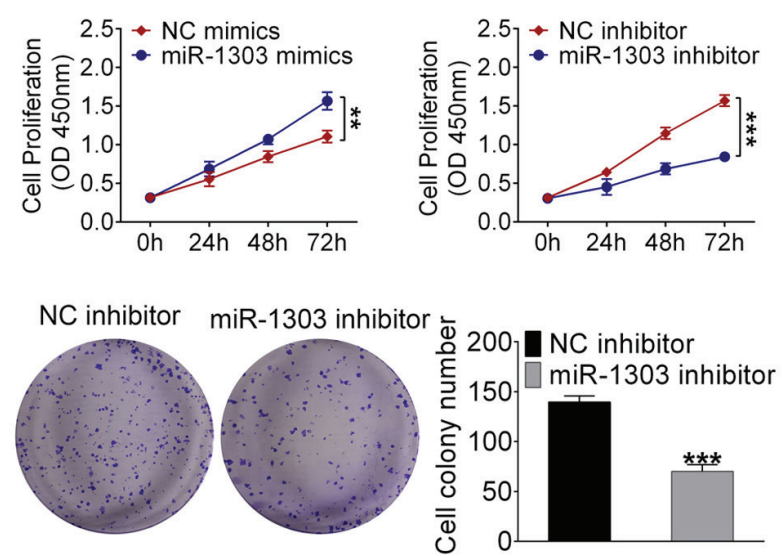

Figure 2. Effects of miR-1303 on prostate cancer cells. DU145 cells were transfected with miR-1303 mimics, miR-1303 inhibitor or negative controls, (A) The expression level of miR-1303 was assessed by reverse transcription-quantitative PCR. Proliferation was evaluated by (B) cell counting kit 8 and (C) a colony formation assay. The migration and invasion of DU145 cells were respectively assessed by (D) a wound healing assay and (E) a Matrigel assay. Magnifications, x100 for (C) and (D); x200 for (E). ${ }^{* * *} \mathrm{P}<0.001,{ }^{* *} \mathrm{P}<0.01,{ }^{*} \mathrm{P}<0.05$ vs. NC mimics or NC inhibitor. DKK3, dickkopf Wnt signaling pathway inhibitor 3; miR-1303, microRNA-1303; NC, negative control; OD, optical density.

Knockdown of miR-1303 inhibits the activity of the Wnt/ $\beta$-catenin signaling pathway by targeting DKK3 in PCa cells. Since it has been reported that DKK3 can function as an inhibitor of Wnt/ $\beta$-catenin signaling pathway (26), the effect of miR-1303 inhibitor on the Wnt/ $\beta$-catenin pathway was investigated by western blotting (Fig. 5A). Compared with the $\mathrm{NC}$ inhibitor, the expression of $\beta$-catenin and its down-stream molecules c-Myc and cyclin D1, were decreased in DU145 cells after transfection with miR-1303 inhibitor $(\mathrm{P}<0.001)$. However, co-transfection with siDKK3 and miR-1303 inhibitor markedly reversed the decreased protein expressions of $\beta$-catenin, cyclin D1 and c-Myc induced by miR-1303 inhibitor $(\mathrm{P}<0.001)$. Furthermore, the distribution and expression of $\beta$-catenin in DU145 cells were measured by immunofluorescence staining (Fig. 5B). miR-1303 inhibitor resulted in a reduction in the number of DU145 cells with $\beta$-catenin expression in the nucleus compared with the control group $(\mathrm{P}<0.001)$, which was reversed after siDKK3 and miR-1303 inhibitor co-transfection $(\mathrm{P}<0.01)$. Accordingly, miR-1303 knockdown effectively suppressed the activity of $\mathrm{Wnt} / \beta$-catenin signaling pathway by regulating DKK3.
Knockdown of miR-1303 suppresses tumor growth in PCa-engrafted mice. To investigate the effects of miR-1303 on tumor growth in vivo, DU145 xenografts were performed to construct a mouse PCa-engrafted model, and the tumor was subsequently treated with miR-1303 inhibitor or negative control by local injection. As shown in Fig. 6A, the growth of tumors was suppressed by miR-1303 inhibitor, which was demonstrated by the lower volume of the tumors treated with miR-1303 inhibitor compared with the control group. In addition, IHC analysis of tumors revealed that the expression of Ki67, an immunohistochemical proliferation marker, was significantly reduced by miR-1303 inhibitor $(\mathrm{P}<0.001$; Fig. 6B). DKK3 expression levels were also increased in tumors treated with miR-1303 inhibitor compared with control tumors $(\mathrm{P}<0.001)$. Therefore, knockdown of miR-1303 may suppress tumor growth in PCa-engrafted model.

\section{Discussion}

Results from the present study indicated that miR-1303 expression was increased in PCa tissues and cell lines. The 
A

$\begin{array}{rrr}\text { DKK3 WT } & 5, & \text {..CUAAUUCUCACAUCCCUCUAAAA... } \\ \text { hsa-miR-1303 } & \text { 3' } & \text { UCUCGUUCUGGGGCAGAGAUUU } \\ \text { DKK3 MUT } & 5, & \text {..CUAAUUCUCACAUCCGAGAUUAA... }\end{array}$

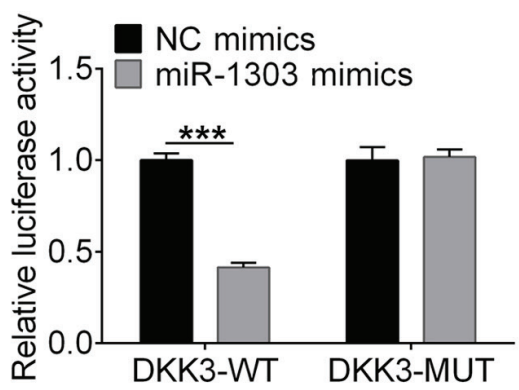

B
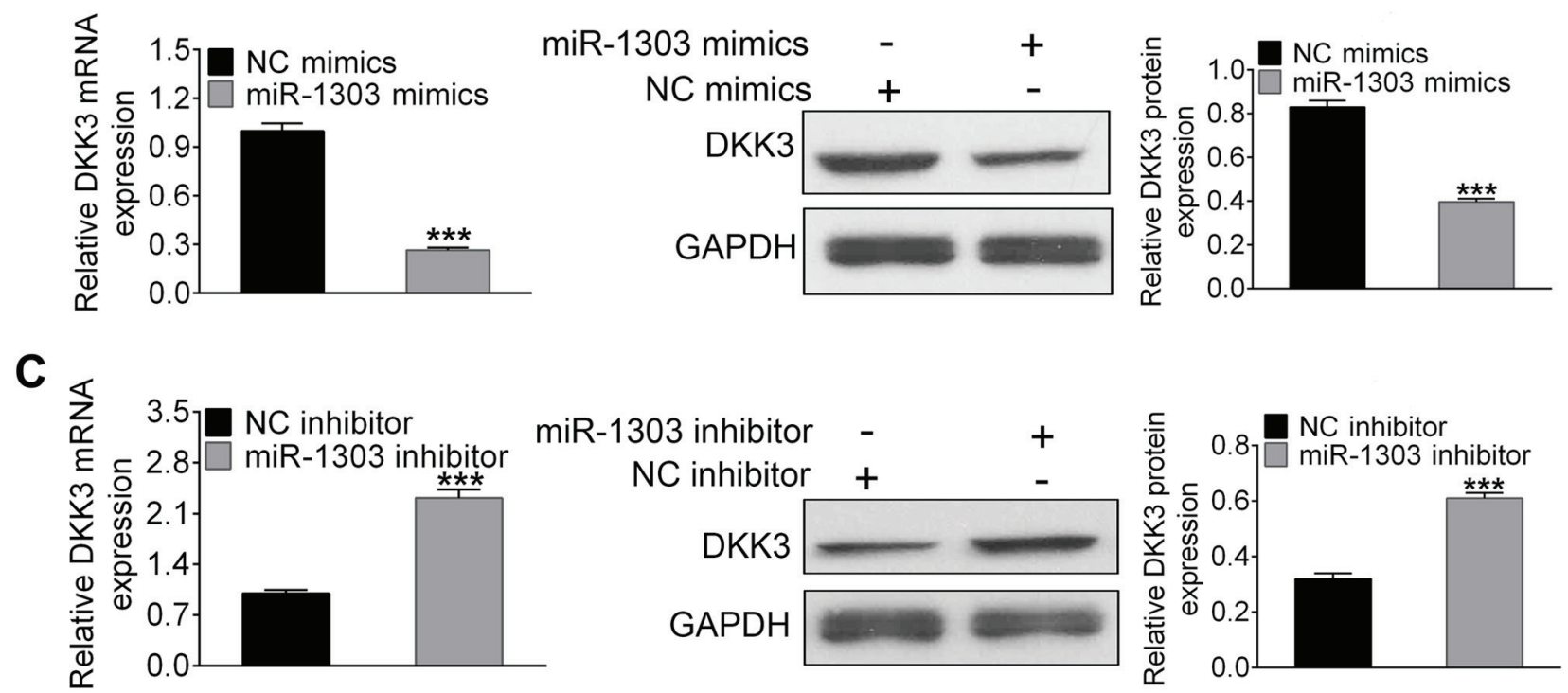

Figure 3. DKK3 is a direct target of miR-1303. (A) TargetScan was used to predict that DKK3 was a direct target of miR-1303. This result was validated by a luciferase reporter assay, comparing WT and MUT target sequences. After DU145 cells were transfected with miR-1303 mimics, miR-1303 inhibitor or controls, (B) reverse transcription-quantitative PCR and (C) western blotting were utilized to detect the mRNA and protein expression of DKK3, respectively. ${ }^{* * * *} \mathrm{P}<0.001$ vs. NC mimics or NC inhibitor. DKK3, dickkopf Wnt signaling pathway inhibitor 3; NC, negative control; miR-1303, microRNA-1303; MUT, mutant; WT, wild-type.

level of miR-1303 was closely associated with higher Gleason scores and a more advanced tumor stage. Patients with $\mathrm{PCa}$ expressed higher levels of miR-1303 also displayed a reduced overall survival rate. High expression of miR-1303 promoted the proliferation, migration and invasion of PCa cells. In addition, inhibition of miR-1303 effectively inhibited the growth of PCa-engrafted tumors in mice. These results indicated that miR-1303 may act as an oncogene in the progression and development of PCa. Thus, miR-1303 may be a potential biomarker for $\mathrm{PCa}$ treatment.

miRNAs have been reported to be closely related with various biological processes, including cell proliferation, metastasis and apoptosis (12). Hence, the role of miRNAs in cancers has been widely studied. Recently, miR-1303 was reported to function as an oncogene in numerous types of tumors. For example, Li et al suggested miR-1303 induced neuroblastoma proliferation via targeting glycogen synthase kinase $3 \beta$ and secreted frizzled related protein 1 (15). Furthermore, miR-1303 overexpression may promote the metastasis and growth of gastric cancer cells by inhibiting claudin 18 expression (16). Additionally, miR-1303 may be a new target for microsatellite instability in colorectal cancer (17). In the present study, it was determined that DKK3 was negatively regulated and identified as a direct target of miR-1303.
DKK3 is designated as a tumor suppressor since its expression is downregulated in many types of tumor, including lung cancer, pancreatic cancer and PCa (27-30). In agreement with previous reports, data from the present study confirmed that DKK3 was downregulated in PCa cells. Additionally, DKK3 was negatively regulated by miR-1303. It is well known that DKK3 can exert a tumor suppressive function via inhibiting the activity of $\mathrm{Wnt} / \beta$-catenin pathway (31). As such, the interaction between $\mathrm{miR}-1303$ and the $\mathrm{Wnt} / \beta$-catenin pathway was studied in this present study.

The Wnt/ $\beta$-catenin pathway is crucial for cellular biological processes such as cell growth and differentiation (32). After activating the $\mathrm{Wnt} / \beta$-catenin pathway, $\beta$-catenin levels increase in the cytoplasm, followed by translocation to the nucleus (33). $\beta$-catenin then activates transcription of target genes mainly containing cyclin D1 and c-Myc (34). Aberrant activation of the Wnt/ $\beta$-catenin pathway is frequently observed in many types of cancers, which contributes to carcinogenesis (35). Wang et al (36) demonstrated that DKK3 could regulate the Wnt $/ \beta$-catenin pathway to induce the apoptosis of cisplatin-resistant lung adenocarcinoma cells. The present study indicated that the raised expression of miR-1303 in PCa cells may inhibit DKK3 expression and activate the Wnt/ $\beta$-catenin pathway, thus promoting cell proliferation, migration and invasion. 


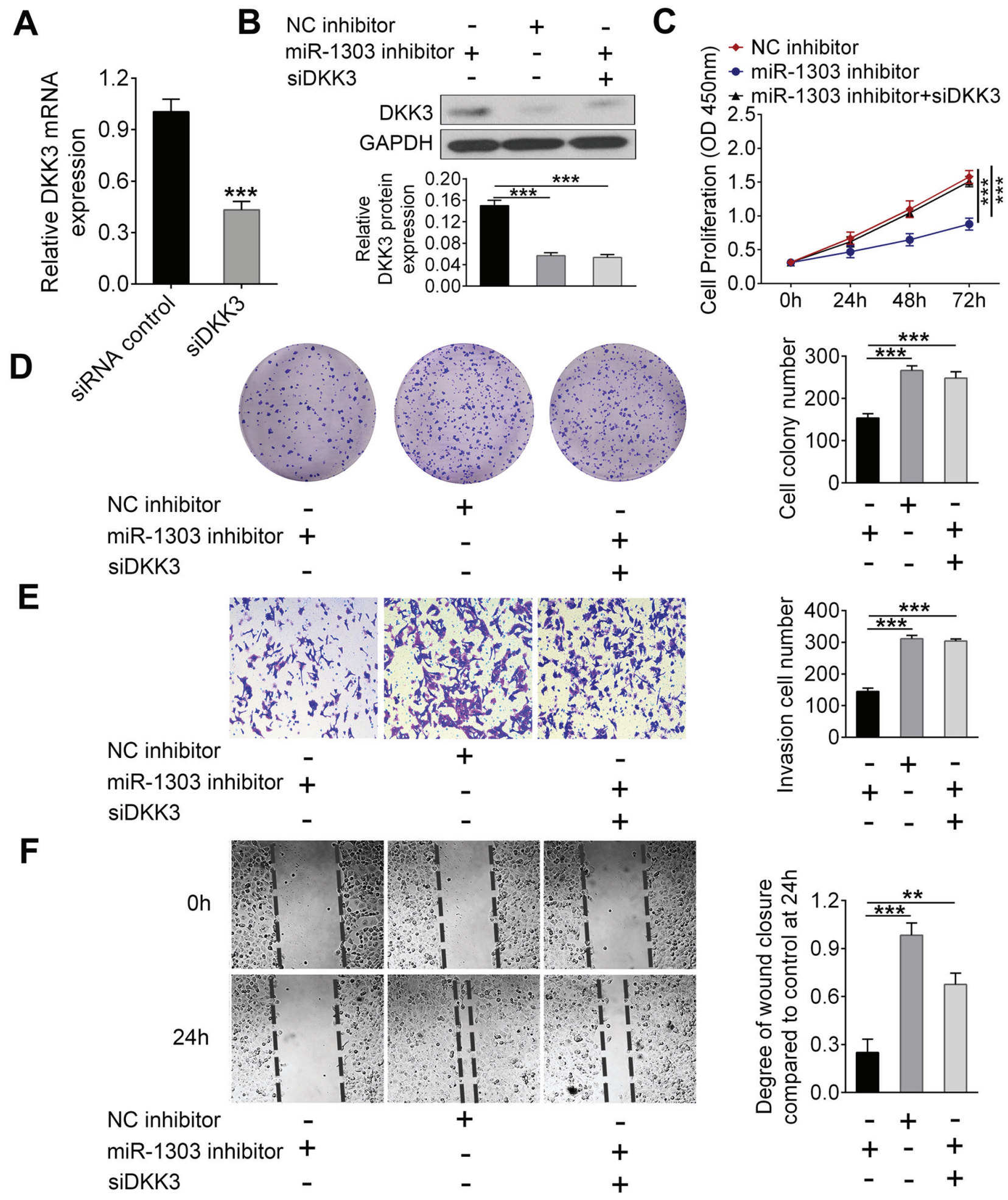

Figure 4. miR-1303 promotes proliferation, migration and invasion of prostate cancer cells through regulating DKK3 expression. DU145 cells were transfected with a combination of miR-1303 inhibitor, siDKK3 or controls. (A) Reverse transcription-quantitative PCR was used to examine the level of DKK3 mRNA expression. (B) Western blotting was used to detect the protein expression level of DKK3. (C) Cell counting kit-8 and (D) colony formation assays were utilized to detect the proliferation of DU145 cells. (E) Matrigel assay and (F) wound healing assay evaluated the cellular invasion and migration, respectively. Magnifications, $\mathrm{x} 100$ for (D) and (F); x200 for (E). ${ }^{* * *} \mathrm{P}<0.001,{ }^{* *} \mathrm{P}<0.01$ vs. miR-1303 inhibitor. DKK3, dickkopf Wnt signaling pathway inhibitor 3; miR-1303, microRNA-1303; NC, negative control; OD, optical density; siDKK3, siRNA for DKK3.

In conclusion, the present study indicated that miR-1303 is upregulated in PCa tissues and cell lines, and that miR-1303 inhibition may effectively suppress the growth of PCa tumors in mice. Moreover, miR-1303 may promote the proliferation, migration and invasion of PCa cells through activating the Wnt/ $\beta$-catenin pathway via regulating DDK3. Therefore, miR-1303 may be regarded as a new biomarker for PCa treatment. A limitation of this study is the lack of analysis in other cell types. Hence, further studies should use more cell lines to further validate the effects of miR-1303 on prostate cancer in 
A
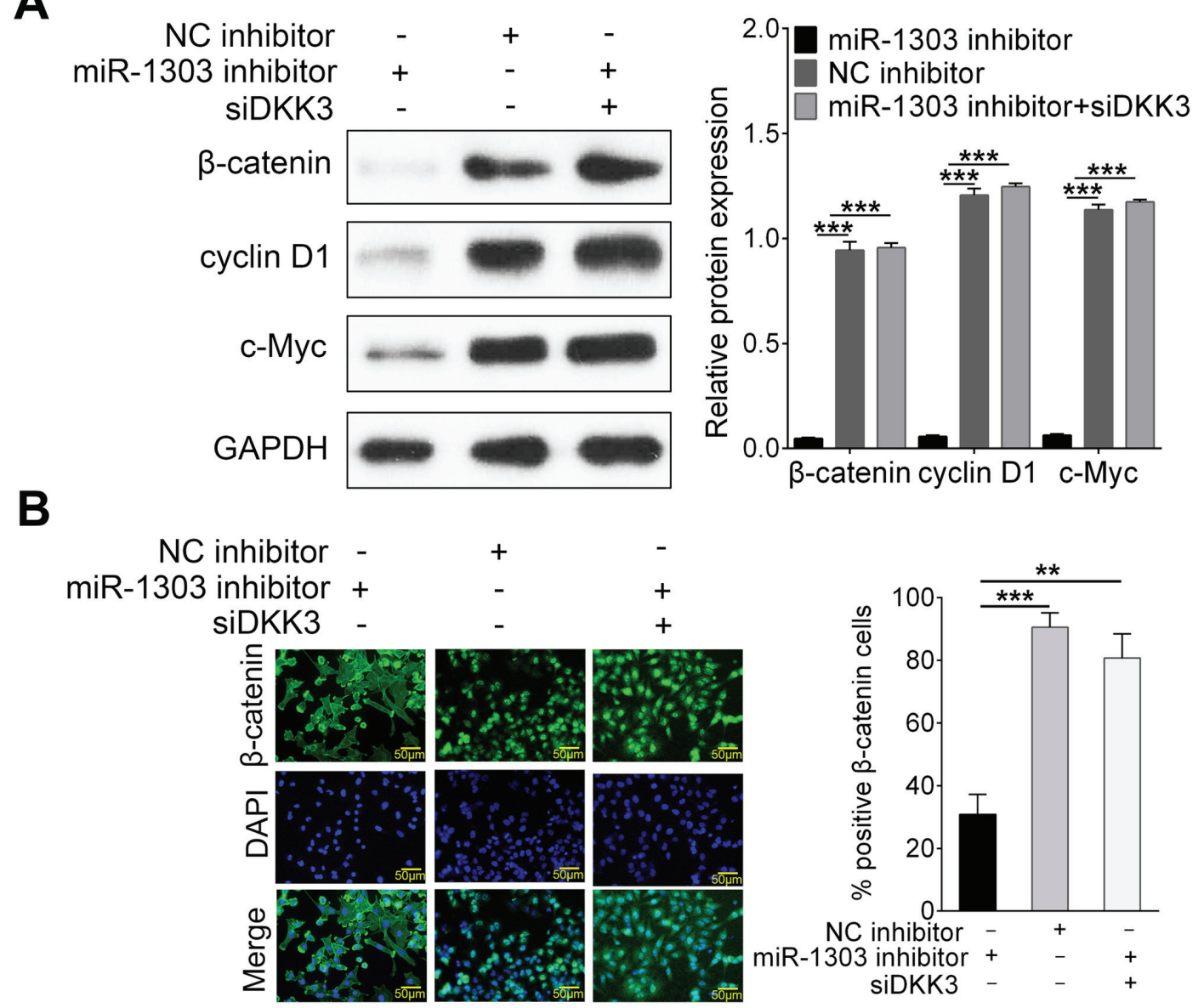

Figure 5. Effects of miR-1303 on the Wnt/ $\beta$-catenin pathway. (A) Western blotting was utilized to detect the protein expression levels of $\beta$-catenin, cyclin D1 and c-Myc, proteins that are involved in the Wnt/ $\beta$-catenin pathway. (B) Representative confocal microscopy images show the distribution of $\beta$-catenin in DU145 cells transfected with NC inhibitor, miR-1303 inhibitor or miR-1303 combined with siDKK3. The \% $\beta$-catenin-positive cells were then counted ${ }^{* * *} \mathrm{P}<0.001,{ }^{* *} \mathrm{P}<0.01$ vs. miR-1303 inhibitor. miR-1303, microRNA-1303; NC, negative control; siDKK3, siRNA for dickkopf Wnt signaling pathway inhibitor 3.
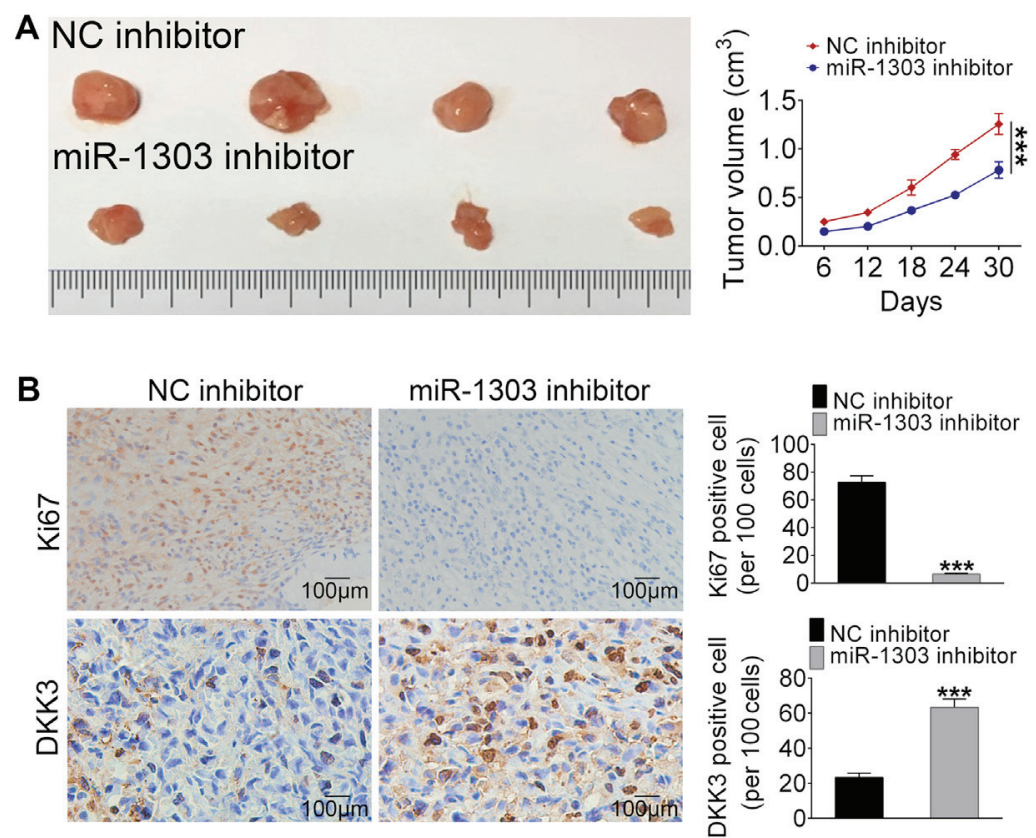

Figure 6. Inhibition of miR-1303 suppresses PCa tumor growth. (A) The growth of tumors was photographed after the PCa-engrafted tumors were treated with miR-1303 inhibitor or NC inhibitor for 30 days. Tumor volumes were recorded every 6 days during the treatment period. (B) Immunohistochemistry staining showed the expression of Ki67 and DKK3 in PCa-engrafted tumors treated with miR-1303 inhibitor compared with NC inhibitor. The percentage positive cells for the markers were then counted. ${ }^{* * *} \mathrm{P}<0.001$ vs. NC inhibitor. DKK3, dickkopf Wnt signaling pathway inhibitor 3; miR1303, microRNA-1303; NC, negative control; PCa, prostate cancer. 
the future. Further studies should also utilize more comprehensive basic research to verify any other mechanisms of action that are involved with the effects of miR-1303 on PCa.

\section{Acknowledgements}

Not applicable.

\section{Funding}

No funding was received.

\section{Availability of data and materials}

The datasets used and/or analyzed during the current study are available from the corresponding author on reasonable request.

\section{Authors' contributions}

BL and WDZ performed the experiments and wrote the manuscript. HYJ collected and analyzed the experimental data. ZDX analyzed the experimental data and revised the manuscript. LW designed the experiments and approved the final version manuscript.

\section{Ethics approval and consent to participate}

The Human Research Ethics Committee of Tongji Hospital approved this experiment. Informed consent was obtained from each patient.

\section{Patient consent for publication}

Not applicable.

\section{Competing interests}

The authors declare that they have no competing interests.

\section{References}

1. Ferlay J, Soerjomataram I, Dikshit R, Eser S, Mathers C, Rebelo M, Parkin DM, Forman D and Bray F: Cancer incidence and mortality worldwide: Sources, methods and major patterns in GLOBOCAN 2012. Int J Cancer 136: E359-E386, 2015.

2. Hoter A, Rizk S and Naim HY: The multiple roles and therapeutic potential of molecular chaperones in prostate cancer. Cancers (Basel) 11: pii: E1194, 2019.

3. Salinas CA, Tsodikov A, Ishak-Howard M and Cooney KA: Prostate cancer in young men: An important clinical entity. Nat Rev Urol 11: 317-323, 2014.

4. Zhan F, Shen J, Wang R, Wang L, Dai Y, Zhang Y and Huang X: Role of exosomal small RNA in prostate cancer metastasis Cancer Manag Res 10: 4029-4038, 2018.

5. Altwaijry N, Somani S and Dufes C: Targeted nonviral gene therapy in prostate cancer. Int J Nanomedicine 13: 5753-5767, 2018.

6. Di Nunno V, Gatto L, Santoni M, Cimadamore A, Lopez-Beltran A, Cheng L, Scarpelli M, Montironi R and Massari F: Recent advances in liquid biopsy in patients with castration resistant prostate cancer. Front Oncol 8: 397, 2018.

7. Shore ND, Karsh L, Gomella LG, Keane TE, Concepcion RS and Crawford ED: Avoiding obsolescence in advanced prostate cancer management: A guide for urologists. BJU Int 115: 188-197, 2015
8. Akram ON, Mushtaq G and Kamal MA: An overview of current screening and management approaches for prostate cancer. Curr Drug Metab 16: 713-718, 2015.

9. Parikh RR, Byun J, Goyal S and Kim IY: Local therapy improves overall survival in patients with newly diagnosed metastatic prostate cancer. Prostate 77: 559-572, 2017.

10. Bryzgunova OE, Konoshenko MY and Laktionov PP: MicroRNA-guided gene expression in prostate cancer: Literature and database overview. J Gene Med 20: e3016, 2018.

11. Gurtan AM and Sharp PA: The role of miRNAs in regulating gene expression networks. J Mol Biol 425: 3582-3600, 2013.

12. Sharma N and Baruah MM: The microRNA signatures: Aberrantly expressed miRNAs in prostate cancer. Clin Transl Oncol 21: 126-144, 2019.

13. Zhu Y, Gu L, Li Y, Lin X, Shen H, Cui K, Chen L, Zhou F, Zhao Q, Zhang, et al: miR-148a inhibits colitis and colitis-associated tumorigenesis in mice. Cell Death Differ 24: 2199-2209, 2017.

14. Wei H, Cui R, Bahr J, Zanesi N, Luo Z, Meng W, Liang G and Croce CM: miR-130a deregulates PTEN and stimulates tumor growth. Cancer Res 77: 6168-6178, 2017.

15. Li Z, Xu Z, Xie Q, Gao W, Xie J and Zhou L: miR-1303 promotes the proliferation of neuroblastoma cell SH-SY5Y by targeting GSK3 $\beta$ and SFRP1. Biomed Pharmacother 83: 508-513, 2016.

16. Zhang SJ, Feng JF, Wang L, Guo W, Du YW, Ming L and Zhao GQ: miR-1303 targets claudin-18 gene to modulate proliferation and invasion of gastric cancer cells. Dig Dis Sci 59: 1754-1763, 2014.

17. El-Murr N, Abidi Z, Wanherdrick K, Svrcek M, Gaub MP, Fléjou JF, Hamelin R, Duval A and Lesuffleur T: MiRNA genes constitute new targets for microsatellite instability in colorectal cancer. PLoS One 7: e31862, 2012.

18. Gao L, Chen B, Li J, Yang F, Cen X, Liao Z and Long X: Wnt/ $\beta$-catenin signaling pathway inhibits the proliferation and apoptosis of U87 glioma cells via different mechanisms. PLoS One 12: e0181346, 2017.

19. Schneider JA and Logan SK: Revisiting the role of Wnt/ $\beta$-catenin signaling in prostate cancer. Mol Cell Endocrinol 462: (Pt A): 3-8, 2018.

20. Kypta RM and Waxman J: Wnt//-catenin signalling in prostate cancer. Nat Rev Urol 9: 418-428, 2012.

21. Li Q, Ye L, Guo W, Wang M, Huang S and Peng X: PHF21B overexpression promotes cancer stem cell-like traits in prostate cancer cells by activating the Wnt/ $\beta$-catenin signaling pathway. J Exp Clin Cancer Res 36: 85, 2017.

22. Flores ML, Castilla C, Gasca J, Medina R, Pérez-Valderrama B, Romero F, Japón MA and Sáez C: Loss of PKC $\delta$ induces prostate cancer resistance to paclitaxel through activation of Wnt/ $\beta$-Catenin pathway and Mcl-1 accumulation. Mol Cancer Ther 15: 1713-1725, 2016.

23. Agarwal V, Bell GW, Nam JW and Bartel DP: Predicting effective microRNA target sites in mammalian mRNAs. Elife 4: 2015.

24. Katase N, Nishimatsu SI, Yamauchi A, Yamamura M and Fujita S: DKK3 overexpression increases the malignant properties of head and neck squamous cell carcinoma cells. Oncol Res 26: 45-58, 2018.

25. Livak KJ and Schmittgen TD: Analysis of relative gene expression data using real-time quantitative PCR and the 2(-Delta Delta C(T)) method. Methods 25: 402-408, 2001.

26. Moskalev EA, Luckert K, Vorobjev IA, Mastitsky SE, Gladkikh AA, Stephan A, Schrenk M, Kaplanov KD, Kalashnikova OB, Pötz O, et al: Concurrent epigenetic silencing of wnt/beta-catenin pathway inhibitor genes in B cell chronic lymphocytic leukaemia. BMC Cancer 12: 213, 2012.

27. Forsdahl S, Kiselev Y, Hogseth R, Mjelle JE and Mikkola I: Pax6 regulates the expression of Dkk3 in murine and human cell lines, and altered responses to Wnt signaling are shown in FlpIn-3T3 cells stably expressing either the Pax6 or the Pax6(5a) isoform. PLoS One 9: e102559, 2014.

28. Shien K, Tanaka N, Watanabe M, Soh J, Sakaguchi M, Matsuo K, Yamamoto H, Furukawa M, Asano H, Tsukuda K, et al: Anti-cancer effects of REIC/Dkk-3-encoding adenoviral vector for the treatment of non-small cell lung cancer. PLoS One 9: e87900, 2014.

29. Guo Q and Qin W: DKK3 blocked translocation of $\beta$-catenin/EMT induced by hypoxia and improved gemcitabine therapeutic effect in pancreatic cancer Bxpc-3 cell. J Cell Mol Med 19: 2832-2841, 2015.

30. Al Shareef Z, Kardooni H, Murillo-Garzon V, Domenici G, Stylianakis E, Steel JH Rabano M, Gorroño-Etxebarria I, Zabalza I, Vivanco MD, et al: Protective effect of stromal Dickkopf-3 in prostate cancer: Opposing roles for TGFBI and ECM-1. Oncogene 37: 5305-5324, 2018. 
31. Veeck J, Bektas N, Hartmann A, Kristiansen G, Heindrichs U, Knüchel R and Dahl E: Wnt signalling in human breast cancer: Expression of the putative Wnt inhibitor Dickkopf-3 (DKK3) is frequently suppressed by promoter hypermethylation in mammary tumours. Breast Cancer Res 10: R82, 2008.

32. Chiurillo MA: Role of the Wnt/beta-catenin pathway in gastric cancer: An in-depth literature review. World J Exp Med 5: 84-102, 2015.

33. Valenta T, Hausmann $\mathrm{G}$ and Basler K: The many faces and functions of $\beta$-catenin. EMBO J 31: 2714-2736, 2012.

34. Ashihara E, Takada T and Maekawa T: Targeting the canonical Wnt/ $\beta$-catenin pathway in hematological malignancies. Cancer Sci 106: 665-671, 2015 .
35. Arend RC, Londono-Joshi AI, Straughn JM Jr and Buchsbaum DJ: The Wnt $/ \beta$-catenin pathway in ovarian cancer: A review. Gynecol Oncol 131: 772-779, 2013

36. Wang Z, Ma LJ, Kang Y, Li X and Zhang XJ: Dickkopf-3 (Dkk3) induces apoptosis in cisplatin-resistant lung adenocarcinoma cells via the Wnt/ $\beta$-catenin pathway. Oncol Rep 33: 1097-1106, 2015.

(i) (3) This work is licensed under a Creative Commons CY NO ND Attribution-NonCommercial-NoDerivatives 4.0 International (CC BY-NC-ND 4.0) License. 